\title{
Considerações sobre a ocorrência da garça-vaqueira, Bubulcus ibis (Linnaeus) (Aves, Ardeidae), em Pernambuco, Brasil
}

\author{
Samanta Della Bella ${ }^{1} \&$ Severino Mendes de Azevedo-Junior ${ }^{1,2}$ \\ ${ }^{1}$ Laboratório de Ornitologia, Departamento de Zoologia, Centro de Ciências Biológicas, Universidade Federal de \\ Pernambuco. Avenida Professor Moraes Rego, Cidade Universitária, 50670-420 Recife, Pernambuco, Brasil. E-mail: \\ sadellabella@bol.com.br \\ ${ }^{2}$ Departamento de Biologia, Universidade Federal Rural de Pernambuco. Avenida Dom Manuel de Medeiros, Dois Irmãos, \\ 52171-900 Recife, Pernambuco, Brasil. E-mail: smaj@ufpe.br
}

\begin{abstract}
On the occurence of the Cattle Egret, Bubulcus ibis (Linnaeus) (Aves, Ardeidae), in Pernambuco, Brazil. The Cattle Egret, Bubulcus ibis (Linnaeus, 1758), originally from Mediterranean Europe and Africa, during the $20^{\text {th }}$ century has spread out its range, also reaching the American Continent. This paper presents information on the occurrence and reproduction of Cattle Egret in Pernambuco, especially in the "Agreste" region. During expeditions to this region, between 2000 and 2003, were found three breeding colonies, one roosting place, and indications of another breeding site. Only one mixed heronry was found. A variable number of $B$. ibis was observed, while driving along different roads in the "Agreste", between May 2002 and April 2003. Movements of Cattle Egret's populations, which are unknown in Brazil, probably influenced this variation. In most cases, Cattle Egrets were observed foraging in association with cattle. The presence of the Cattle Egret in the "Agreste" of Pernambuco seems to benefits the cattle industry, but its occurrence might impacts the native fauna.

KEY WORDS. Agreste, colonization, foraging, heronries, impacts.
\end{abstract}

RESUMO. A Garça-vaqueira, Bubulcus ibis (Linnaeus, 1758), originária da Europa Mediterrânea e da África, durante o século XX expandiu sua distribuição, alcançando inclusive o Continente americano. Este trabalho reúne dados sobre sua ocorrência e reprodução em Pernambuco, sobretudo no Agreste. Durante excursões a esta região, realizadas entre os anos de 2000 e 2003, foram localizadas três colônias reprodutivas, um sítio de pernoite, além de um local com vestígios indicativos de reprodução. Apenas uma colônia mista foi avistada. $O$ número de indivíduos de B.ibis, observado nas margens de diferentes estradas do Agreste, percorridas entre maio de 2002 e abril de 2003, apresentaram grande variação. Essa variação pode estar relacionada a flutuações populacionais em razão de deslocamentos característicos da espécie, desconhecidos no Brasil. A maioria das garças foi observada em atividade de forrageamento, associadas ao gado. A presença da Garça-vaqueira no Agreste parece trazer benefícios para a atividade pecuária, mas essa ocorrência pode causar impactos à fauna nativa.

PALAVRAS CHAVE. Agreste, colonização, forrageamento, impactos, ninhais.

A Garça-vaqueira, Bubulcus ibis (Linnaeus, 1758), originalmente vivia confinada ao Velho Mundo (Rice 1956). A primeira observação desta espécie nas Américas foi feita na Guiana Inglesa, no final do século XIX (Wetmore 1963). Em 40 anos B. ibis se disseminou através do norte da América do Sul, para os Estados Unidos, Canadá, América Central e México (Сrosвy 1972), tornando-se, nesse breve intervalo, a garça mais numerosa da América do Norte (Fogarty \& Hetrick 1973).

Seu primeiro registro no Brasil foi feito em 1964, por SICK (1965), na Ilha de Marajó, Estado do Pará. Como previsto pelo mesmo autor, atualmente a garça tem sua ocorrência e reprodução disseminada por todo o país, mas ainda existem poucas informações sobre sua reprodução no Brasil (SıcK 1997). A presença de B. ibis no nordeste foi registrada somente em 1985 (Teixeira et al. 1987). Em Pernambuco, os maiores bandos de Garça-vaqueira foram observados na região do Agreste setentrional e meridional, onde se desenvolve a pecuária bovina (AzEvedo-Júnior 1997).

Essa espécie é encontrada freqüentemente próxima a bovinos, capturando presas espantadas pelo gado pastando, elevando assim, sua taxa de captura e diminuindo o gasto de energia (Heatwole 1965, Тhompson et al. 1982). Apesar de primariamente insetívoras, essas aves são oportunistas, obtendo uma variedade de outros itens alimentares, como invertebrados 
aquáticos, pequenos anfíbios, répteis, mamíferos, aves e peixes (Lowe-McConnell 1967, Fogarty \& Hetrick 1973, Gasset et al. 2000).

No fim da tarde as garças partem dos locais de forrageamento em direção aos seus sítios ou colônias de pernoite, os quais podem se transformar em ninhais (VINCENT 1947). Durante o período reprodutivo, a Garça-vaqueira sofre modificações na plumagem, na coloração do bico e das partes nuas (RidDelL 1944), nidificando em colônias mistas com outras espécies de garças (e.g. Buerkle \& Mansell 1963, Dusi \& Dusi 1970, McCrimmon 1978, Burguer 1982, Ruiz et al. 1981, MADdock \& BAXTER 1991).

Tendo em vista a escassez de informações sobre a Garçavaqueira no nordeste do Brasil, objetivou-se, nesse trabalho, reunir observações sobre sua ocorrência e reprodução em Pernambuco, sobretudo na região Agreste do estado, e tecer algumas considerações sobre essa ocupação.

\section{MATERIAL E MÉTODOS}

O presente estudo foi conduzido no Agreste do estado de Pernambuco (Fig. 1), zona fitogeográfica caracterizada por uma vegetação de caatinga, com índice pluviométrico intermediário entre a zona da Mata e o Sertão (SALES et al. 1998).

As colônias foram localizadas observando-se a ocorrência de bandos de $B$. ibis nas margens das estradas e com base em informações obtidas com a população local, durante excursões realizadas entre os anos de 2000 e 2003. Quando localizadas, as colônias tiveram o número de indivíduos estimado com o auxílio de binóculos e a posição exata obtida com o auxilio de GPS. Para a estimativa do número total de aves presentes, dividiu-se o grupo em blocos de acordo com o tamanho da colônia (Bівву et al. 1992). Essas contagens foram efetuadas no fim do dia, quando todos os indivíduos retornam para pernoite.

Para avaliação da ocorrência de B. ibis no Agreste ainda foram registradas todas as garças avistadas, bem como a atividade que estavam realizando (forrageamento, repouso ou vôo), durante percursos realizados com automóvel. Uma excursão mensal foi realizada de maio de 2002 a abril de 2003, porém em junho, agosto, setembro e novembro de 2002 a ocorrência de chuvas nos trajetos impossibilitou a observação. Essa amostragem foi feita de forma aleatória, sendo que diferentes estradas foram percorridas (Fig. 1C) entre as 7:30 e 14:00 h, totalizando 2.459 km e 49,3 h de observação.

\section{RESULTADOS}

No Agreste pernambucano foram avistadas três colônias reprodutivas e uma colônia de pernoite de $B$. ibis, além de vestígios da ocorrência de um sítio de reprodução. Todas apresentaram um aspecto geral semelhante, sendo construídas nas margens de açudes, sobre galhos da Jurema-branca Piptadenia obliqua (Pers) Maclar (Leguminosae) e da Algarobeira Prosopsis juliflora (SW) DC (Leguminosae).

Duas colônias reprodutivas foram localizadas em julho de

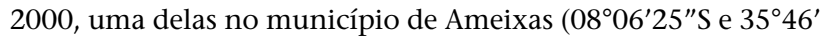

$\left.40^{\prime \prime} W\right)$ e outra em São Bento do Una $\left(08^{\circ} 29^{\prime} 07^{\prime \prime}\right.$ S e $\left.36^{\circ} 21^{\prime} 23^{\prime \prime} W\right)$, com aproximadamente 1.500 e 10.000 indivíduos adultos (reprodutivos e não reprodutivos), respectivamente. Essas localidades foram novamente visitadas em maio de 2002, quando as colônias haviam se dissolvido. Em Ameixas, o açude estava com cerca de 30\% do volume de água observado anteriormente, e em São Bento do Una a maioria das árvores havia sido cortada.

O terceiro sítio reprodutivo foi avistado em novembro de 2001, no município de Brejão ( $09^{\circ} 00^{\prime} 37^{\prime \prime}$ S e $\left.36^{\circ} 31^{\prime} 01^{\prime \prime} \mathrm{W}\right)$, com cerca de 12.000 indivíduos. Em maio de 2002, a colônia possuía cerca de 6.000 indivíduos de B. ibis e um casal de Garça-brancagrande, Ardea alba (Linnaeus, 1758), construindo ninho. A partir de julho de 2002, a colônia começou a sofrer perturbações antrópicas, quando contava com aproximadamente $8.600 \mathrm{~B}$. ibis e 12 casais $A$. alba. Em abril de 2003, possuía apenas 500 indivíduos e a maioria das árvores utilizadas pelas garças havia sido derrubada. Esta foi a única colônia mista observada no Agreste.

Em janeiro de 2003 foi localizada uma colônia de pernoite no município de Pombos (08 $08^{\prime} 29^{\prime \prime}$ S e $\left.35^{\circ} 23^{\prime} 45^{\prime \prime} \mathrm{W}\right)$, com cerca de 250 Garças-vaqueiras. Alguns destes indivíduos apresentavam plumagem de reprodução, porém foram encontrados apenas dois ninhos abandonados, caídos no chão. No mesmo período, foram observados vestígios de ninhos de $B$. ibis em uma fazenda no município de Altinho (08 $29^{\prime} 23^{\prime \prime}$ S e $\left.36^{\circ} 03^{\prime} 34^{\prime \prime} \mathrm{W}\right)$, apesar de não ter sido avistado nenhum indivíduo. Relatos dos moradores da localidade sugerem a ocorrência de reprodução da Garça-vaqueira nos anos anteriores. As colônias localizadas estão representadas na figura 2 .

Durante os percursos pelas estradas do Agreste pernambucano (Fig. 1C), foram observados 1.724 indivíduos de B. ibis (Tab. I). Os locais em que foram avistadas as garças estão indicados na figura 2 . Do total de $B$. ibis observadas, $48,5 \%$ ocorreram numa única excursão, em maio de 2002. O valor obtido do desvio padrão mostrou uma assimetria em relação à média de indivíduos avistados por quilômetro $(\mathrm{M}=6,6$ e $\mathrm{S}=7,7)$ nos diferentes meses e trajetos. O trajeto B (figura $1 \mathrm{C}$ ), percorrido em diversos meses (Tab. I), apresentou uma média de 5,7 (desvio padrão: $S=3,0$ ) indivíduos avistados por quilômetro. Este mesmo trajeto soma $35,8 \%$ do total de garças observadas.

A maioria das aves avistadas nas margens das estradas estava em atividade de forrageamento. Destas, 69,5\% encontrava-se associada com o gado bovino. Entre as aves que estavam em repouso, 37,7\% encontravam-se aglomeradas com bovinos também descansando e $42,6 \%$ estavam próximas a açudes ou brejos. Apenas $0,6 \%$ das aves observadas estavam em atividade de vôo (Tab. II). Em todos os meses de observação foram registradas garças com plumagem de reprodução.

\section{DISCUSSÃO}

É bem aceito que a menor distância entre a África e a América do Sul (Senegal-Rio Grande do Norte) não teria sido a rota preferencial das Garças-vaqueiras para a colonização do Novo Mundo, já que os registros de sua presença nas Guianas 


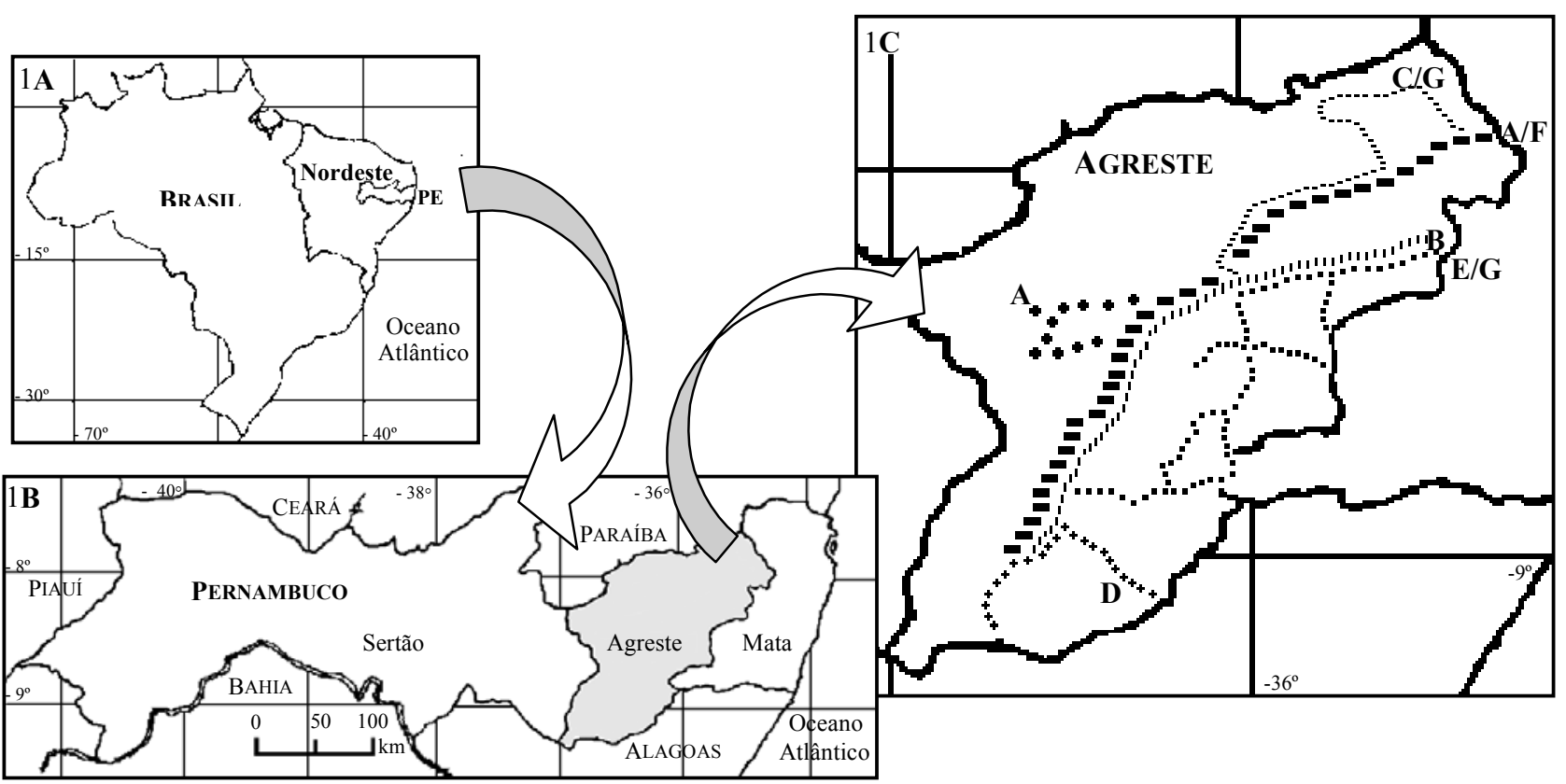

Figura 1. Área de estudo. (1A) Brasil, em destaque: nordeste, Pernambuco; (1B) Pernambuco, em destaque: Agreste; (1C) Agreste de Pernambuco com a representação das estradas percorridas durante o estudo: cada trajeto está representado por um símbolo e a letra correspondente, sendo apenas os trajetos A e $\mathrm{G}$ representados por duas simbologias.

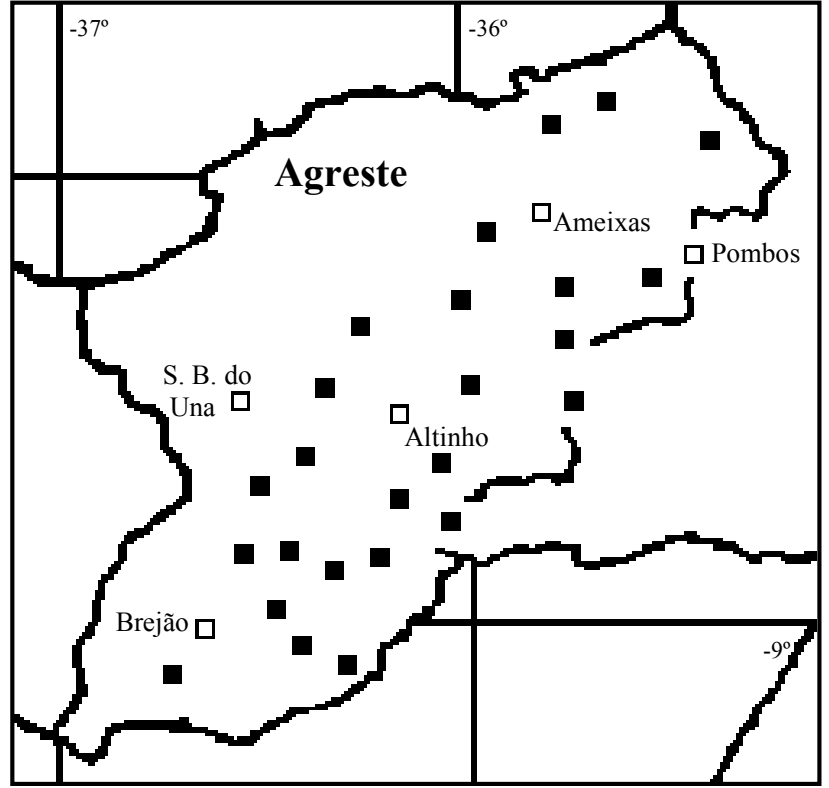

Figura 2. Agreste pernambucano. Os quadrados plotados na figura representam os locais onde foram avistados os bandos de $B$. ibis durante os percursos realizados pelas estradas da região. Os símbolos vazados representam os locais onde foram localizados sítios reprodutivos ou de pernoite, com o respectivo nome do município. são muito anteriores aos brasileiros. Além disso, se as aves fizessem este trajeto encontrariam ventos desfavoráveis (CROSBY 1972). Contudo, isto não exclui a possibilidade de que alguns grupos tenham chegado diretamente ao Brasil pelo nordeste, como sugere a ocorrência de $B$. ibis e outros ardeídeos do Velho Mundo em Fernando de Noronha e nos Rochedos de São Pedro e São Paulo (Teixeira et al. 1987).

Apesar da falta de registros anteriores a 1985, a ocorrência da Garça-vaqueira no nordeste pode ter se dado muitíssimo antes, com o já sugerido por Teixeira (1992), quando avaliou a presença dessa ave nas pinturas do "Libri Principis" e nas descrições de Marcgrave do século XVII. Acredita-se que colonização do Brasil teria ocorrido pelo norte (SICK 1997), irradiandose posteriormente tanto para o nordeste quanto para o sul do país. Somando-se a isto, a chegada de novos grupos vindos diretamente da África, pois as garças provavelmente ainda chegam nas Américas vindas do Velho Mundo (Browder 1973).

São numerosos os açudes construídos no Agreste pernambucano, que têm a finalidade de suprimento de água ao gado. Estes, quando margeados por árvores, tornam-se locais ideais para o estabelecimento de uma colônia, ao lado das pastagens fornecedoras de alimento. Uma colônia de garças se estabelece em determinada área quando existe uma estrutura para a construção de ninhos e um hábitat de alimentação adequado (LeITÃo \& FARINHA 1998), sendo que no caso da Garça-vaqueira, uma variedade de ambientes (e.g. CunNingham 1965, Lowe-McConnelL 
Tabela I. Relação das excursões realizadas e resultados obtidos. (Trajeto): mês/ano/código do percurso realizado, esses percursos estão representados na figura 1C. (D) distância percorrida, em quilômetros; (T) tempo de observação, em horas; (N B. ibis) número de indivíduos de $B$. ibis avistados; (\% B. ibis) número de Garças-vaqueiras observadas em cada trajeto em relação ao total observado, expresso em porcentagem; (Ind/10 km): número Garças-vaqueiras avistadas em relação à quilometragem percorrida, expresso em número de indivíduos a cada dez quilômetros. Total de quilômetros percorridos, horas de observação e indivíduos avistados. Média (M) e desvio padrão (S) do número de indivíduos avistados em relação à quilometragem percorrida.

\begin{tabular}{|c|c|c|c|c|c|}
\hline Trajeto & $\mathrm{D}(\mathrm{Km})$ & $T(h)$ & Número $B$. ibis & $\%$ B. ibis & Ind/10km \\
\hline Maio/2002/A & 284 & 7,7 & 837 & 48,5 & 29,5 \\
\hline Julho/2002/B & 214 & 4,0 & 194 & 11,3 & 9,1 \\
\hline Outubro/2002/B & 214 & 4,0 & 66 & 3,8 & 3,1 \\
\hline Dezembro/2002/C & 260 & 5,8 & 126 & 7,3 & 4,8 \\
\hline Janeiro/2003/B & 214 & 3,0 & 114 & 6,6 & 5,3 \\
\hline Janeiro/2003/D & 105 & 3,5 & 57 & 3,3 & 5,4 \\
\hline Janeiro/2003/E & 226 & 4,3 & 77 & 4,5 & 3,4 \\
\hline Fevereiro/2003/B & 214 & 4,0 & 185 & 10,7 & 8,6 \\
\hline Março/2003/F & 213 & 5,0 & 2 & 0,1 & 0,1 \\
\hline Abril/2003/B & 214 & 3,0 & 58 & 3,4 & 2,7 \\
\hline Abril/2003/G & 301 & 5,0 & 8 & 0,5 & 0,3 \\
\hline Total & 2459 & 49,3 & 1724 & 100 & $M=6,6 S=7,7$ \\
\hline
\end{tabular}

Tabela II. Atividades realizadas pelas garças observadas, durante os percursos pelas estradas do Agreste pernambucano, expressas em porcentagem de ocorrência. As garças, que estavam em atividade de forrageamento e repouso, foram distribuídas em três categorias de acordo com a presença ou não de gado ou alagados próximos.

\begin{tabular}{lclr}
\hline Atividade & Ocorrência (\%) & \multicolumn{1}{c}{ Atividade } & Ocorrência (\%) \\
\hline Forrageamento & 67,5 & Forrageando com o gado bovino & 69,5 \\
& & Forrageando com eqüinos & 7,4 \\
& & Forrageando sem pastadores & 23,1 \\
\hline Repouso & 31,9 & Repousando próximo ao gado & 37,7 \\
& & Repousando próximo de açudes & 42,6 \\
& & Repousando sem gado ou água & 29,7 \\
\hline Vôo & & & \\
\hline
\end{tabular}

1967, JeNni 1969, Pomeroy 1975) parece preencher estes requisitos.

Os proprietários dos açudes não apreciam a presença das garças, pois a água, altamente eutrofizada, devido ao grande aporte de nutrientes vindos da colônia (fezes, pelotas, ovos e carcaças), torna-se imprópria para o gado. A derrubada das árvores e, possivelmente, tiros ou fogos de artifício, justificaram o abandono de sítios de reprodução, pelo menos em duas das colônias observadas (São Bento do Una e Brejão).

Apesar da Garça-vaqueira caracteristicamente reproduzir em colônias mistas com outros ardeídeos, como observado no ninhal de Brejão, existem relatos de colônias exclusivas de B. ibis (Lehmann 1959, Weber 1975, Bachir et al. 2000), como ocorreu em Ameixas e São Bento do Una.

Há uma grande variação na extensão do período reprodutivo de $B$. ibis em diferentes partes do mundo. $\mathrm{Na}$ Espanha a reprodução tem duração de quatro a cinco meses (Prosper \& Hafner 1996), no norte da África foi estimada em quatro meses (BACHIR et al. 2000), assim como na Flórida (WEBER 1975). No Texas esse período apresentou-se mais prolongado, com duração de sete a nove meses (Telfair 1994). E, nas Guianas, Lowe-MCConNell (1967) encontrou dois períodos reprodutivos no ano, sugerindo que as mesmas garças se reproduzem em ambas as estações. As bases dessa variação provavelmente residem na sazonalidade climática que interferirá de maneira mais ou menos severa dependendo da região do globo.

\section{Revista Brasileira de Zoologia 21 (1): 57-63, março 2004}


No Brasil, os registros não se mostram menos variáveis, o período reprodutivo foi observado entre os meses de agosto e fevereiro em São Paulo (Toledo 2000), o ano todo no Rio de Janeiro (SICK 1997), e entre outubro a dezembro no Rio Grande do Sul (Belton 1994). No nordeste tem-se registro de reprodução na Paraíba nos meses de março, abril e agosto, sendo sugerida a reprodução ao longo de todo o ano (NASCIMENTo 1999). Monitoramentos se fazem necessários para uma melhor avaliação dessa variação. As avistagens de garças com plumagem reprodutiva nos diversos meses de observação no Agreste pernambucano sugerem que, pelo menos fenotipicamente, a Garça-vaqueira poderia se reproduzir ao longo do ano todo.

As aves se alimentam a uma certa distância ao redor da colônia até atingir um limite onde já não compensa percorrer, mesmo que exista alimento. Para uma colônia com 650 casais de $B$. ibis, foi estimado um raio de 10 a $12 \mathrm{~km}$ como área de forrageamento (LeITão \& Farinha 1998). Se as populações de Garças-vaqueiras do nordeste brasileiro se comportarem da mesma forma, espera-se encontrar ainda outros sítios reprodutivos e de pernoite, já que muitos bandos forrageadores, incluindo animais com plumagem reprodutiva, foram observados bem mais distantes das colônias localizadas.

A grande variação do número de Garças-vaqueiras observadas nas margens das estradas do Agreste pernambucano se justifica pela não sistematização dos percursos, meses e do número de horas das excursões, impossibilitando conclusões no âmbito quantitativo. A análise de apenas um percurso em diferentes meses, como o trajeto B, ainda apresentou considerável variação no número de indivíduos avistados por quilômetro, sugerindo, que pode também estar contribuindo para esse resultado, a ocorrência de migrações e deslocamentos característicos da espécie (BROWDER 1973). Esses deslocamentos são desconhecidos no Brasil e podem, no nordeste, estar relacionados com a sazonalidade dos períodos de chuva, que constitui fator condicionante da disponibilidade de alimento. Estudos da ocorrência, flutuação populacional e marcação de indivíduos precisam ser desenvolvidos para o conhecimento do comportamento deste fenômeno no Brasil.

Como os trajetos foram percorridos principalmente no período da manhã, era esperado que a maioria das aves estivesse executando suas atividades de alimentação, durante as quais ocorrem breves períodos de descanso. As Garças-vaqueiras deixam o local de pernoite ao amanhecer em busca de alimento, retornando apenas ao anoitecer, salvo os indivíduos com prole, que retornam durante o dia para a colônia a fim de alimentar seus filhotes (Lehmann 1959). Assim, indivíduos em atividade de vôo serão encontrados com maior freqüência apenas durante o crepúsculo.

Concordando com os hábitos característicos da espécie, foi observada uma alta proporção de garças forrageando em associação com o gado bovino no Agreste, frente às outras possibilidades de procura de alimento (individualmente, em grupos intraespecíficos ou em associação com outros pastadores).
Nessa relação encontra-se uma das principais razões para sua expansão, o crescimento da indústria da pecuária tornou disponível para as Garças-vaqueiras um vasto e novo território, pois nenhum grande mamífero pastador vivia nos trópicos do Novo Mundo anteriormente (Rice 1956).

As garças observadas descansando com bovinos podem também estar em busca de mais uma oportunidade de obter alimento. Apesar da possibilidade de simplesmente estarem sincronizando seu período de repouso com o gado (THOMPSON et al. 1982), Garças-vaqueiras são observadas capturando principalmente moscas atraídas por estes animais descansando (Vincent 1947, Burns \& Chapin 1969).

A proporção de aves avistadas próximas a alagados sugere uma preferência por estes locais. Mais uma vez, o 'repouso' pode estar relacionado à obtenção de alimento nas margens da água. Mora (1992) observou uma elevada freqüência de aves forrageando em campos irrigados. Esse sistema certamente difere do que as garças encontram nas águas paradas dos açudes, porém elas podem, de maneira semelhante, estar se aproveitando da disponibilidade de presas que ali se concentram.

A presença da Garça-vaqueira no Agreste parece trazer benefícios para a atividade pecuária, podendo controlar a população de insetos herbívoros, muitas vezes pragas (SICK 1997), prováveis competidores primários com o gado pelas pastagens (Jenni 1969). Além de terem participação importante na predação dos carrapatos quando já desprendidos do corpo do gado (GonZales 1995).

Porém, a despeito destes benefícios para a pecuária, a ocorrência de B.ibis em áreas de descanso e reprodução das garças nativas tem causado preocupação entre ornitologistas (Fogarty \& Hetrick 1973). Bennetts et al. (2000) mostram que o sucesso reprodutivo de um ardeídeo está declinando desde a chegada da Garça-vaqueira e, em outro caso, a ocorrência dessa diminuição é atribuída à competição e ao aumento do distúrbio causado pela agressividade de B. ibis na colônia (Burger 1978).

A ocupação da Garça-vaqueira e seus efeitos adversos sobre a fauna nativa não se restringem apenas a áreas desmatadas para a criação de gado, como indica sua presença no Parque Nacional Marinho de Fernando de Noronha. O primeiro registro da espécie neste arquipélago foi obtido em 1986 (Teixeira et al. 1987). Em maio de 1987 Antas et al. (1990) observaram 12 Garças-vaqueiras no arquipélago, porém em nova visita, em julho do mesmo ano, nenhum indivíduo foi avistado. De um visitante ocasional, se tornou residente e, num curto intervalo de tempo, a população se multiplicou, sendo, em 2000, observada inclusive a reprodução no arquipélago (J.M. Silva, com. pess.). Essa ocorrência demonstra, além da capacidade irradiativa, a velocidade do estabelecimento desse ardeídeo. Nesse ambiente, impactos potenciais podem advir da ocupação de áreas de reprodução de aves costeiras, além de em outras ilhas $B$. ibis ser observada predando ovos, filhotes e pássaros (Cunningham 1965, Feare 1975). Considerações tam- 
bém devem ser feitas sobre a avistagem dessas garças se alimentando do lagarto endêmico de Fernando de Noronha, Euprepis atlanticus (Schmidt, 1945), Scincidae (J.M. Silva, com. pess.).

Dessa forma torna-se evidenciada a ocorrência e reprodução de B. ibis em Pernambuco, salientando-se que as razões que permitira a expansão e o estabelecimento desse ardeídeo durante o último século em diferentes partes do mundo residem no seu comportamento alimentar oportunístico (GASSET et al. 2000), na sua biologia reprodutiva, além das mudanças ambientais devido às atividades humanas que devem ser consideradas em qualquer avaliação sobre o sucesso da garça (LowEMCConnell 1967). Inicialmente representadas pelo desmatamento e introdução do gado e subseqüentemente pela disponibilização de locais com a concentração de resíduos sólidos (FEARE 1975). Existindo apenas uma minoria de espécies de aves que têm se beneficiado das conseqüências das atividades humanas (Pomeroy 1975), entre elas a Garça-vaqueira.

\section{AGRADECIMENTOS}

À UFPE e a CAPES pelo apoio financeiro. A UFRPE pela viabilização de transporte para as excursões ao Agreste. A Mariinha e Aparecida pelo apoio logístico em Brejão. Ao J. M. Silva pelas informações. A C. Fedrizzi e C. J. Carlos pela leitura crítica e sugestões. Aos Referis pelas contribuições.

\section{REFERÊNCIAS BIBLIOGRÁFICAS}

Antas, P.T.Z.; A. Fillipini \& S.M. Azevedo-Junior. 1990. Anilhamento de aves-oceânicas e/ou migratória no arquipélago de Fernando de Noronha em 1987 e 1988. Anais do IV Encontro Nacional de Anilhadores de Aves, Pernambuco, p. 13-17.

Azevedo-Junior, S.M. 1997. Colonização da Garça-Boieira Bubulcus ibis em Pernambuco, Brasil. Airo, Lisboa, 8 (1/2): 48-50.

Bachir, A.S.; H. Hafner, J.N. Tourene \& S. Doumandji. 2000. Structure de L'habitat et biologie de reproduction du heron garde-boeuf, Bubulus ibis, dans une colonie de la valée de la Soummam (Petite Kabylie, Algerie). Revue D'Ecologie-La Terre et La Vie, Paris, 55 (1): 33-43.

Belton, W. 1994. Aves do Rio Grande do Sul: distribuição e biologia. São Leopoldo, Ed. Unisinos, 584p.

Bennets, R.E.; M. Fasola; H. Hafner \& Y. Kayser. 2000. The influence of environmental and density-dependent factors on reproductive parameters of Little Egrets in the Camargue, south France. Auk, Lawrence, 117: 634-639.

BibBy, J.C.; N.D. Burgues \& D.A. HiLl. 1992. Bird census techniques. London, Academic Press, 257p.

BRowder, J.A. 1973. Long distance movements of Cattle Egrets. Bird Banding, Boston, 44 (3): 158-170.

Buerkle, U. \& D. Mansell. 1963. First nesting record of the Cattle Egret (Bubulcus ibis) in Canada. Auk, Lawrence, 80 (2): 378379.
BURGER, J. 1978. Competition between Cattle Egrets and native north american herons, egrets, and ibises. Condor, California, 80: 15-23

- 1982. On the nesting location of Cattle Egrets Bubulcus ibis in south african heronries. Ibis, London, 124 (4): 523-528.

Burns, E.C. \& J.B. Chapin. 1969. Arthropods in diet of Cattle Egret Bubulcus ibis in southern Lousiana. Journal of Economic Entomology, Washington, 62 (3): 736-738.

Crosby, G.T. 1972. Spread of the Cattle Egret in the western hemisphere. Bird-Banding, Boston, 43 (3): 205-212.

Cunningham, R.L. 1965. Predation on birds by Cattle Egret. Auk, Lawrence, 82 (3): 502-503.

Dusi, J.L. \& R.T. Dusi. 1970. Nesting success and mortality of nestlings in a Cattle Egret colony. Wilson Bulletin, Ohio, 82 (4): 458-460.

FEARE, C.J. 1975. Scavenging and kleptoparasitism as feeding methods of Seychelles Cattle Egrets Bubulcus ibis. Ibis, London, 117 (3): 388.

Fogarty, M.J. \& W.M. Hetrick. 1973. Summer foods of Cattle Egrets in north central Florida. Auk, Lawrence, 90 (2): 268280.

Gasset J.W.; T.H. FolK; K.J. Alexy, K.V. Miller; B.R. Chapman; F.L Boyd \& D.I. Hall. 2000. Food habits of Cattle Egrets on St. Croix, U.S. Virgin Islands. Wilson Bulletin, Ohio, 112 (2): 268-271.

Gonzales, J.C. 1995. O Controle do Carrapato do Boi. Porto Alegre, Ed. Autor, 79p.

Heatwole, H. 1965. Some aspects of the association of Cattle Egrets with Cattle. Animal Behaviour, London, 13 (1): 79 83.

JENNI, D.A. 1969. A study of the ecology of four species of herons during the breeding season at Lake Alice Alachua County, Florida. Ecological Monographs, Durhan, 39 (3): 245-270.

Lehmann, F.C. 1959. Observations on the Cattle Egret in Colômbia. Condor, California, 61 (4): 256-269.

Leitão, D. \& J.C. Farinha. 1998. Método para estimar a área de alimentação em redor de uma colônia de garças. Airo, Lisboa, 9 (1/2): 9-15.

Lowe-McConnell, R.H. 1967. Biology of the immigrat Cattle Egret Ardeola ibis in Guyana, South America. Ibis, London, 109 (2): 168-179.

Maddock, M. \& Baxter, G.S. 1991. Breeding success of Egrets related to rainfall: a six-year australian study. Colonial Waterbirds, Kansas, 14 (2): 133-139.

McCrimmon, D.A. 1978. Nest site characteristics among five species of herons on the North Carolina coast. Auk, Lawrence, 95 (2): 267-280.

Mora, M.A. 1992. Habitat use by foraging Cattle Egrets in the Mexicali Valley, Baja California. Wilson Bulletin, Ohio, 104 (1): 142-148.

Nascimento, J.L.X. 1999. Registros de ninhais de garças 
(Ciconiiformes, Ardeidae) na Paraíba, Brasil. Airo, Lisboa, 10 (1): 39-42.

Pomeroy, D.E. 1975. Birds as scavengers of refuse in Uganda. Ibis, London, 117 (1): 68-81.

Prosper, J. \& H. Hafner. 1996. Breeding aspects of the colonial ardeidae in the Albufera de Valencia, Spain: population changes phenology, and reproductive success of the three most abundant species. Colonial Waterbirds, Kansas, 19 (Special Publication1): 98-107.

Rice, D.W. 1956. Dynamics of range expansion of Cattle Egrets in Florida. Auk, Lawrence, 73 (2): 259-266.

RidDell, W.H. 1944. The Buff-Backed Heron, Ardeola ibis ibis (Linnaeus). Ibis, London, 86 (4): 503-516.

Ruiz, X.; L. Jover \& A. Montori. 1981. Primeros datos sobre la reproducción de la gacilla bueyera - Bubulcus ibis ibis (L.) en el Delta del Ebro, Tarragona (España). Publicaciones del Departamento de Zoologia, Barcelona, 7: 77-86.

SAles, M.F., S.J. MaYo \& M.J.N. Rodael. 1998. Plantas vasculares das Florestas Serranas de Pernambuco: Um checklist da flora ameaçada dos Brejos de Altitude. Recife, Ed. Universidade Federal Rural de Pernambuco, 130p.

SIcK, H. 1965. Bubulcus ibis (L.) na Ilha de Marajó, Pará: Garça ainda não registrada no Brasil. Anais da Academia Brasileira de Ciências, Rio de Janeiro, 37: 567-570.
SICK, H. 1997. Ornitologia Brasileira. Rio de Janeiro, Ed. Nova Fronteira, 836p.

Teixeira, D.M.; J.B. Nacinovic \& F.B. Pontual. 1987. Notes on some birds of northeast Brazil (2). Bulletin of the British Ornithologists' Club, London, 107 (4): 151-157.

Teixeira, D.M. 1992. As fontes do paraíso - Um ensaio sobre a ornitologia no Brasil holandês (1624-1654). Revista Nordestina de Biologia, João Pessoa, 7 (1/2): 1-149.

Telfair II, R.C. 1994. Cattle Egret (Bubulcus ibis). In: A. Poole \& F. GILl (Eds). The Birds of North America. Life histories for the $21^{\text {st }}$ Century. Washington: The American Ornithologists'Union, 31p.

Toledo, M.C.B. 2000. Temporal and spatial patterns of nesting within a breeding colony in southeastern Brazil. Revista de Biociências, Taubaté, 6 (2): 23-30.

Thompson, C.F.; S.M. Lanyon \& K.M. Thompson. 1982. The influence of foraging benefits on association of cattle egrets with Cattle. Oecologia, Berlin, 52 (2): 167-170.

VInCENT, J. 1947. Habits of Bubulcus ibis, the Cattle Egret, in Natal. Ibis, London, 89 (4): 489-491.

Weber, W.J. 1975. Notes on Cattle Egret breeding. Auk, Lawrence, 92 (1): 111-117.

Wetmore, A. 1963. An early record of the Cattle Egret in Colômbia. Auk, Lawrence, 80 (3): 547.

Recebido em 11.VII.2003; aceito em 20.I.2004. 